\title{
EXPANSIÓN CAÑERA EN EL VALLE DEL CAUCA Y RESISTENCIAS COMUNITARIAS (COLOMBIA)
}

\section{Sugarcane Geographic Expansion in River Valley of Cauca and Community in Resistance (Colombia)}

\author{
HERNANDO URIBE-CASTRO ${ }^{1}$ \\ ${ }^{1}$ Magíster en Sociología, estudiante del Doctorado en Ciencias Ambientales, Universidad del Valle. Profesor y \\ coordinador del Grupo de Investigación en Conflictos y Organizaciones, Universidad Autónoma de Occidente.
}

E-mail: huribe@uao.edu.co

\begin{abstract}
Este artículo de investigación tiene como objetivo presentar los factores sociales que posibilitaron la expansión de la agroindustria cañera en el valle geográfico del río Cauca ubicado en el suroccidente colombiano, y visibilizar cómo algunas comunidades, afectadas social y ambientalmente por esta actividad, realizaron acciones colectivas de resistencias. La metodología de elaboración de este artículo consistió en el método de la indagación documental que consistió en la revisión teórica y conceptual de la producción realizada sobre la agroindustria cañera en el Valle del Cauca y que se encuentra dispuesta en las bases de datos del sistema de bibliotecas de la Universidad del Valle, así como de las principales universidades de la región. También consistió en el acceso y revisión de la documentación y fuentes históricas dispuestas en el Archivo Histórico de Cali, así como los centros de documentación del Departamento de Historia y de Geografía de la Universidad del Valle. También, la revisión de la documentación oficial existente en el Centro de Documentación de la Corporación Autónoma Regional del Valle del Cauca (CVC en adelante).
\end{abstract}

Palabras clave: Resistencia socioambiental, Agroindustria cañera, Sistema socioecológico, Valle geográfico, Río Cauca.

\begin{abstract}
This research paper aims to present the ( historical, political and economic ) social factors that enabled the rise and expansion of the sugarcane industry in the geographic Cauca River Valley is located in southwestern Colombia, and show how as some communities, socially and environmentally affected by this activity, you made collective actions of resistance. The methodology of preparing this article consisted of a qualitative approach that combined the methods of documentary and historical inquiry. The documentary research consisted of theoretical and conceptual review of the production made on the sugarcane industry in the Valle del Cauca and which is disposed in the databases of the library system of the University del Valle, as well as major universities region. The historical method in turn consisted of access and review of documents and historical sources arranged in the Historical Archive of Cali and documentation centers of the Department of History and Geography at the Universidad del Valle. Also the review of existing official documentation in the Documentation Centre of the Autonomous Regional Corporation of the Cauca Valley, CVC .
\end{abstract}

Keywords: Social and environmental resistance, Sugarcane industry, Socio-ecological system, Geographical, Cauca river valley. 


\section{INTRODUCCIÓN}

El valle geográfico del río Cauca se ubica en el suroccidente colombiano y se extiende desde el norte del Departamento del Cauca hasta el Departamento de Risaralda (Figura 1). A lo largo del siglo $\mathrm{XX}$, esta área se transformó por factores políticos y socioeconómicos que conllevaron hacia un nuevo sistema territorial al pasar de unas tierras donde predominaban las actividades agrícolas y ganaderas con la existencia de un número importante de humedales, hacia unas tierras dominadas por el monopolio del cultivo de la caña de azúcar.

Entre los factores responsables de esta transformación se destacan: la incursión de capitales económicos en el campo inyectados por empresarios dedicados a la agroindustria, los álgidos procesos de urbanización e industrialización, el desarrollo de infraestructuras agenciadas desde el Estado y las empresas privadas, así como la existencia de una elite política que logró influenciar los espacios de toma de decisión local, regional y nacional para imponer la agroindustria como motor del desarrollo regional.

En este contexto, algunas comunidades campesinas afrodecescendientes del norte del Cauca, se vieron obligadas a vender sus propiedades a los ingenios, convirtiéndose en trabajadores asalariados como corteros. Perdieron sus propiedades y migraron hacia los poblados cercanos como Puerto Tejada, Corinto, o hacia las principales ciudades como Cali y Bogotá. Y unas más, han permanecido en sus lugares desarrollando actividades agroecológicas, defendiendo su recurso agua y/o protegiendo su territorio con la no venta de sus propiedades a los ingenios azucareros. También resistiendo mediante la denuncia de los efectos de la quema de la caña, el desabastecimiento del agua, las precarias condiciones laborales o enfrentando las dificultades del acceso a los servicios públicos domiciliarios. Recuperar algunos casos históricos de estas resistencias es trascendental porque logran evidenciar que a lo largo de la historia regional se presentaron luchas sociales que reivindicaron la defensa de la comunidad y del ambiente frente a las elites de poder y del Estado.

De este modo, este artículo se encuentra estructurado de la siguiente manera: se presentará, primero, las definiciones conceptuales necesarias que permitirán comprender este fenómeno; segundo, se hará mención al método utilizado en el artículo que consistió en la combinación de la indagación documental y el método histórico. Tercero, se abordarán los determinantes históricos que posibilitaron la conformación agroindustrial en el Valle del Cauca y, finalmente, se dará paso a la presentación de las implicaciones de la expansión de los cultivos de caña en el sistema socioecológico, dando prioridad a las luchas y resistencias presentes sobre esta parte del territorio colombiano. Al terminar se harán algunas reflexiones de cierre.

\section{MÉTODOS}

En este artículo se recurrió a la indagación documental. Desde la indagación documental, la estrategia fue la búsqueda exhaustiva de los temas relacionados con la agroindustria cañera en las principales bases de datos de la biblioteca de la Universidad del Valle y de las universidades de la región para la elaboración del estado de arte. En estas bases de datos se privilegiaron los textos impresos como monografías de pregrado, trabajos de grado de maestría y tesis doctorales. Se accedieron a artículos de revistas especializadas de las ciencias sociales y las ingenieras del ámbito local y regional. Estas bases de datos también arrojaron información necesaria para la construcción del marco teórico y conceptual sobre la teoría de la acción colectiva (tanto documentos de reflexión teórica como de estudios de caso concreto); producción sobre los temas de resistencias sociales (reflexión teórica y estudios de caso), así como información sobre sistemas sociecológicos y ecología política. Estas cuatro son las dimensiones sobre las que se sustenta teórica y epistemológicamente este artículo. Adicional a esto, la búsqueda de información se concentró también en documentación estadística sobre producción agrícola y estudios académicos. Aportó la revisión de información histórica especializada en el Archivo histórico de la ciudad de Cali, así como la información dispuesta y existente en el Centro de Documentación del Departamento de Historia y Geografía de la Universidad del Valle y el Centro de Documentación de la CVC. También se hizo uso de la hemeroteca de la Biblioteca Mario Carvajal para ubicar en los archivos de prensa local y regional, como El País, información sobre luchas sociales en esta parte del país.

\section{MARCO TEÓRICO Y CONCEPTUAL}

Para comprender el fenómeno de los factores que posibilitaron el auge y expansión de la caña de azúcar y las reacciones de resistencia de las comunidades, es necesario concretar conceptual y epistemológicamente este fenómeno. Estas son: sistema socioecológico, resistencias y ecología política.

\section{Sobre sistema socioecológico}

Un concepto clave en este artículo es sistema socioecológico. Para autores como Sherman Farhad se utiliza para referirnos a un concepto holístico, sistémico e integrador del "ser humano-en-la naturaleza". Se entiende como un sistema complejo y adaptativo en el que hacen referencia a los procesos de acoplamiento e interacción entre los sistemas 
sociales (cultura, economía, organización social y política) y los sistemas ecológicos (naturaleza) en un espacio-tiempo determinado. Interacciones que se expresan desde diferentes formas de acción humana como extracción de recursos, pesca, producción de alimentos, que interfieren los mecanismos naturales en los ecosistemas, así como también a través de las inundaciones, variaciones climáticas, cambios de estación, transformación de suelos, que siendo fenómenos naturales producen efectos sobre los sistemas sociales (Salas et al. 2012). Las interacciones pueden ser materiales (flujos de recursos, dinero, materias primas, alimentos, residuos y personas) así como no materiales como flujos de información y conocimiento, valores, decisiones, acciones políticas, etc. (Salas et al. 2012).

Salas y sus colegas identifican tres tipos de sistemas socioecológicos:

Sistemas Diseñados-controlados (SDC): "Son sistemas fabricados por los seres humanos. Por consiguiente, resultan de un diseño intencional y se caracterizan porque el comportamiento de sus componentes es rigurosamente controlado. Dentro de este tipo de sistemas se pueden mencionar las industrias, las obras de infraestructura, los productos tecnológicos como los carros, los aviones, los computadores, entre otros ejemplos" (Salas et al. 2012).

Los sistemas no diseñados-no controlados (SNDNC). "Estos sistemas no se fabrican ni se diseñan intencionalmente pero sí se heredan natural y/o culturalmente. Por esa razón, no siguen estrictamente decisiones humanas aunque sí pueden ser intervenidos e influenciados por estas $\mathrm{y}$, por consiguiente, son de escaso control. De ahí que se consideren de alta incertidumbre" (Salas et al. 2012).

Finalmente, los sistemas diseñados - no controlados (SDNC), que es acorde y que interesa, según el caso particular del valle geográfico del río Cauca en la medida en que: "Son sistemas diseñados intencionalmente para seguir un conjunto de reglas de operación que guíen su comportamiento, aunque sus componentes no son fabricados. Por esta razón tiene un alto grado de autonomía y el comportamiento del sistema es parcialmente controlable, aunque si puede ser intervenido y afectado por las acciones y decisiones humanas" (Salas et al. 2012).

Ahora bien, existen unas estructuras jerárquicas en la que los sistemas (humano-naturaleza) que componen el sistema socioecológico están interconectados a través de ciclos adaptativos de crecimiento, acumulación, reestructuración y renovación que, comunicados entre ellos, posibilitan la sostenibilidad. Holling (2002) a este proceso lo denomina Panarquía. De este modo, Wong, considera que "el término - panarquía- es utilizado para describir un concepto que explica la naturaleza evolutiva de sistemas adaptativos complejos y se centra en los elementos críticos que afectan o desencadenan la reorganización y transformación de un sistema (Gunderson \& Holling 2001, Holling 2001)." (Guderson \& Holling 2001 citado por Wong 2006).

Para Holling (2001), existen tres propiedades que conforman el ciclo adaptativo y el estado futuro de un sistema: El potencial inherente de un sistema que está disponible para el cambio y que potencialmente determina la gama de futuras opciones. Esta propiedad puede ser pensado, como la "riqueza" de un sistema; La controlabilidad interna de un sistema, es decir, el grado de conexión entre las variables internas que controlan el proceso, una medida que refleja el grado de flexibilidad o rigidez de tales controles, como su sensibilidad o no a la perturbación; La capacidad adaptativa, es decir, la capacidad de recuperación del sistema, una medida de su vulnerabilidad a los impactos inesperados o impredecibles. Esta propiedad puede ser pensada como el opuesto a la vulnerabilidad del sistema (Holling 2001).

Cuando los ecosistemas y las sociedades enfrentan perturbaciones, estos pueden tener la capacidad de recuperación ante las situaciones adversas. La Resiliencia puede considerarse como una propiedad emergente resultado de un conjunto de procesos naturales y sociales dados en el sistema socioecológico. La resiliencia está vinculada con la posibilidad de recuperar sus condiciones originales y el sostenimiento de los diferentes ciclos panárquicos, que retroalimentan el proceso natural ecosistémico. Entonces en un lugar determinado tanto los elementos de la naturaleza como los organismos, las comunidades y sus entornos pueden ser resistentes y resilientes, aunque no siempre la resiliencia está directamente relacionada con la resistencia. Autores como Thompson (2011) expresan que existen casos donde;

"los ecosistemas puede ser muy resilientes pero poco resistentes a una determinada perturbación. Por ejemplo, muchos bosques boreales no son especialmente resistentes al fuego pero si sumamente resilientes al mismo, y normalmente se recuperan por completo tras la quema al cabo de algunos años. Por lo general, la mayor parte de los bosques naturales, especialmente los bosques primarios viejos, son tanto resilientes como resistentes a diversos tipos de cambio" (Thompson 2011).

\section{Sobre acción colectiva de resistencia}

La perspectiva teórica Tilly (1978) es la movilización de recursos y las oportunidades políticas que define la acción colectiva como "aquella llevada a cabo por un grupo de 
personas que comparten unos intereses comunes, que se organizan en unas estructuras más o menos formales y que ponen en marcha acciones movilizadoras, todo ello bajo una determinada estructura política que facilitará o dificultará su influencia en el poder en función de sus características. Es decir, se trata de una acción conjunta que persigue unos intereses comunes y desarrolla unas prácticas de movilización concretas para alcanzarlos en un sistema sociopolítico y económico determinado" (Tilly 1978).

El modelo de análisis posee cuatro factores: i) Los intereses comunes que son compartidos y que resultan de cómo unos actores sienten y perciben que como grupo son afectados por las acciones y comportamientos de ese "otro"; ii) La organización (formal o informal) a través de la cual el grupo pretende alcanzar una estructura coherente para alcanzar su objetivo; iii) La movilización de recursos que hace referencia al mecanismo por el cual un grupo de individuos pasa de ser un colectivo pasivo, a un colectivo activo de la vida pública haciendo uso de los diferentes tipos de recursos humanos, técnicos, tecnológicos y económicos; iv) Las oportunidades políticas que refiere al razonamiento básico del grupo en términos de ubicar el momento claro y preciso para actuar. Estas categorías (intereses, organización, recursos y oportunidad) que son del grupo al ponerse frente a otro opositor se convierte en un modelo político (Tilly 197852).

En este marco, las comunidades despliegan repertorios de acción colectiva como por ejemplo, las resistencia socioambientales, que haría referencia a todas aquellas formas de acción colectiva de defensa, denuncia, insatisfacción y reacción que realiza un grupo de personas organizadas de modo más o menos formal para enfrentar a un "otro" opositor (que puede ser otra comunidad, el Estado o agentes privados locales, nacionales o globales), cuyas acciones, estrategias, discursos, proyectos o planes, producen afectaciones nocivas al ambiente territorial de las comunidades.

\section{La perspectiva de la ecología política}

Si bien, existen importantes aportes desde los años setentas cuando es acuñado el concepto por Eric Wolf (1972) en su texto "Ownership and Political Ecology" y de la tradición marxista de Martínez-Alier y James O'Connor en la revista Ecología Política entre 1992 y 2004, en nuestra propuesta interesan los aportes desde el pensamiento latinoamericano: Enrique Leff (2003) y Arturo Escobar (1999).

Desde el marco latinoamericano, la ecología política se define como un campo teórico-práctico que debe abordar los conflictos de la distribución ecológica y las relaciones de poder (Leff 2003). En este sentido, este campo analiza aquellos procesos de significación, valoración y apropiación de los elementos de la naturaleza más allá del determinismo y reduccionismo económico superando de este modo la valoración económica de la naturaleza o la asignación de normas ecológicas a la economía (Leff 2003).

De la ecología política emergen conceptos fundamentales como nuevos discursos para comprender la complejidad del ambiente, como por ejemplo el de Distribución ecológica (las asimetrías o desigualdades sociales, espaciales, temporales en el uso que hacen los humanos de los recursos y servicios ambientales, comercializados o no) (Leff 2003); deuda ecológica (concepto estratégico movilizador de conciencia de resistencia a la globalización del mercado y sus instrumentos de coerción financiera, cuestionando la legitimidad de la deuda económica de los países pobres) (Leff 2003). Así, la ecología política trabaja por la desnaturalización de la naturaleza y se encamina a una visión más que constructivista, una visión y acción política que expresa relaciones, discursos y acciones de poder.

La ecología política se define entonces como aquel campo que redefine las relaciones entre cultura, ambiente, desarrollo y movimientos sociales (Escobar 1999). Desde esta perspectiva, la ecología política incorpora nociones de biodiversidad, resistencias, territorios, economías y desarrollos alternativos, todo ellos en los marcos de la identidad. La ecología política tendría la tarea de pensar y reflexionar sobre las relaciones entre los sistemas económicos, ecológicos y culturales, por ello, la ecología política es interdisciplinar. (Escobar 1999).

La ecología política trata de comprender los procesos y estrategias usados para la colonización de la naturaleza, así como los discursos, las tecnologías y las prácticas usadas por los centros de poder, en contraposición a las comunidades y pueblos que resisten y enfrentan mediante la acción colectiva y los movimientos sociales. Se enfoca entonces, a comprender cómo los eventos de conflicto socioambiental son estímulos para la construcción de la sociedad civil y de su conciencia ambiental. Por tanto, la ecología política observa los contextos de producción y reproducción de injusticias socioambientales, develando los discursos con los que se imponen estas realidades.

En este sentido, la ecología política aporta a la crítica del capitalismo y sus trampas en la sociedad. Pone en evidencia la relación utilitaria entre las elites del poder global con los gobiernos que ponen sus Estados a merced de la voluntad de los impulsores y la fuerza del Mercado, donde la naturaleza de los entornos locales, que le pertenecen a estas comunidades (afrodescendientes, indígenas y campesinas) pasan al dominio de las corporaciones globales, produciéndose así conflictos socioambientales, que pueden generar procesos represivos por parte del Estado para salvaguardar los intereses de las empresas y respuestas 
colectivas de las comunidades como resistencias a estos embates producidos en nombre del desarrollo.

La ecología política pone en cuestión la concepción moderna de desarrollo reducido a la idea de crecimiento económico, indicadores de eficiencia y calidad y reducción de la obligación social del Estado. Ante esto, la ecología política destaca los movimientos antisistémicos de índole global así como los de fuerza local, donde comunidades ancestrales o nativas y campesinas enfrentan poderes corporativos globales que cooptaron las agencias del Estado. Comunidades afrodescendientes, indígenas y campesinas defendiendo sus territorios, la vida y su dignidad de vivir en ambientes y entornos sanos y distantes de las fuerzas del capital.

\section{Factores históricos que posibilitaron la expansión cañera en el Valle del Cauca}

Las anteriores bases teóricas son importantes para comprender el fenómeno de la expansión cañera en esta parte de Colombia. La descripción histórica que a continuación se presenta, pretende mostrar los determinantes sociales, políticos y económicos que confluyeron para que exista hoy en el valle geográfico del río Cauca no solo una espacio dedicado sólo a la caña de azúcar, sino también para que exista un espacio que fue ideado por las elites de poder regional, haciendo uso incluso de agencias del Estado como la CVC. Estos hechos tendrán como consecuencia, tal como se verá más adelante, efectos nocivos tanto para el ecosistema natural como para la sociedad. Por ello, el concepto de sistema socioecológico así como el de ecología política son importantes. Estos eventos históricos que se muestran aquí, van a estar muy relacionados con las formas como las comunidades locales ejercen resistencias, bien como grupos defensores de sus territorio ancestral de la que participan comunidades indígenas y negras, o bien como trabajadores de los ingenios (proletarios agrícolas) que demanda mejores condiciones laborales a través de distintas formas de huelgas a lo largo del tiempo mediante los sindicatos de trabajadores o de las organizaciones comunitarias.

Históricamente, estas tierras estaban habitadas por comunidades indígenas que fueron extinguidas con la llegada de la conquista y de la colonización española. Se asentaron sobre este territorio haciendas para desarrollar actividades extractivas de minería, ganadería y agricultura. Hacia finales del siglo XIX e inicios del siglo XX, el modelo de hacienda empieza a transformarse por la incorporación de capitales sobre las áreas rurales que permitieron el surgimiento, desarrollo y ampliación de la actividad agroindustrial (Vásquez 2000), que aprovechó las ventajas geográficas y el conjunto de condiciones naturales como luminosidad todo el año y componentes del suelo ricos para la agricultura.
El auge y expansión de la actividad agroindustrial tiene como hito histórico 1880, época de la modernización e instalación de equipos extranjeros como alambiques y molinos para la transformación de la caña en azúcar y la consolidación de su cadena productiva donde el transporte por ferrocarril se convertiría en factor para el transporte del producto. Luego, entre 1927 y 1929, se presentan no solo la modernización de los ingenios con fluido eléctrico (Rojas 1983), sino también las recomendaciones de las Misiones Inglesas y Chardón que propusieron, por una parte, una mayor dedicación de la tierra al cultivo de la caña de azúcar y, por otra parte, la necesidad de dar apertura a más ingenios azucareros (Reyes 2008, Perafán 2013). A estas recomendaciones se suman las coyunturas económicas causadas por los efectos de la segunda guerra mundial en términos de lo que ello implico para el aumento de la demanda de azúcar como producto básico alimenticio.

En el marco de esta coyuntura de posguerra, también conocida como "guerra fría", la competencia entre Estados Unidos y la Unión Soviética por el liderazgo mundial produce una tensa situación en los países dependientes de estas economías, pues se fragmenta el mundo en dos bloques: socialista y capitalista. Los Estados Unidos, como potencia occidental inicia su total control a la expansión del socialismo y el comunismo en América Latina a partir de la alianza con gobiernos militares en América Latina, Asia y África. En América Latina, se produce la Revolución Cubana en 1959 como expresión de la expansión del comunismo, a lo que reacciona Estados Unidos con su bloqueo económico en1960. El bloqueo a Cuba, abre las puertas a la producción de azúcar en Colombia (Bermúdez 2004), y desde ese momento, la proliferación y tendencia de la dedicación del cultivo cañero sobre todo el territorio del valle geográfico del río Cauca.

Si bien, estos elementos históricos se corresponden con dinámicas globales en la que intervienen hechos estructurales de los conflictos mundiales, en términos de los acontecimientos locales, es necesario resaltar la creación de la Corporación Autónoma Regional del Valle del Cauca (CVC en adelante). Este hecho es fundamental para comprender la dinámica azucarera. Tal como lo muestra la Tabla 1, desde la década de los años 40 se venía preparando el terreno político, económico para la construcción y consolidación de una institución que, siendo agencia del Estado, fuera capaz de liderar los principales proyectos que impulsarían el desarrollo regional y privado. Ya se habían realizado estudios que mostraban claramente la intención de la elite política y empresarial en impulsarlos: estudio de la presa salvajina (1943-1944), Estudio para el desarrollo hidráulico del Valle del Cauca (1945-1947), el proyecto General de Electrificación (1949), el Anteproyecto de Irrigación del Río Timba (1951), el 
Proyecto Agua Blanca (1951) y el Plan de Desarrollo económico de la Cuenca Hidrográfica del Alto Cauca (1952) (CVC 2004).

De todos estos, cabe resaltar el "Proyecto Aguablanca" que antecede al surgimiento de la CVC y aparece que como propuesta de trabajo de la firma del grupo OLAP (Olarte, Ospina, Arias y Payán Ltda.), para el control de inundaciones, drenaje y riego en 1951. ${ }^{1}$ Este proyecto implicaba tres tipos de estudios: levantamientos topográficos preliminares, estudios hidrológicos y estudios de suelos. El punto sobre el estudio de los suelos es de vital importancia, porque es ahí donde radica la principal justificación para la intervención de la zona con el desarrollo y construcción de un conjunto de infraestructuras que transformarían la zona de inundación y que además proveería de rentabilidad a la inversión tanto del Estado como de las empresas privadas. El trabajo técnico consistía, entonces, en determinar los trabajos que deberían de adelantarse para el sistema de drenaje e irrigación de tierras en el valle geográfico. ${ }^{2}$ Con este proyecto se podría impulsar la agricultura de cacao, frutales, hortalizas, azúcar, plátanos, maíz, etc., que tenían demanda en el mercado de consumo. Se sugieren pastizales para la cría de vacas y producción de leche. Según OLAP, la calidad de los suelos los hace más aptos para cultivos que de ganadería por lo que se sugiere desplazar la ganadería extensiva a las faldas de la cordillera o a otras zonas. El estudio de suelos de OLAP considera que la zona de Aguablanca "constituye la despensa de ciudades de la importancia de Cali y poblaciones vecinas. Las áreas de este proyecto deben dedicarse exclusivamente a la producción de artículos de primera necesidad: leche, arroz, frijoles, hortalizas, frutas, cacao, etc., siendo la caña de azúcar también un cultivo remunerativo en la región." (OLAP 1950). Según lo señalan Velásquez \& Jiménez (2004):

"Si bien, las inundaciones por desbordes del río Cauca fueron uno de los principales limitantes al desarrollo agrícola de la región, la escasez de agua en épocas de intenso verano, la ausencia de infraestructura y energía y el limitado conocimiento de la agricultura, fueron otros aspectos que se consideraron como importantes obstáculos al desarrollo potencial de la región (SAG 1995). Todos estos fueron fuertes argumentos para la creación de la Corporación Autónoma Regional del Cauca - CVC,

\footnotetext{
${ }^{1}$ Se suscribe el contrato No. 3287 de enero 24 de 1950, entre el Departamento del Valle del Cauca y OLAP.

${ }^{2}$ El énfasis del proyecto se expresa claramente: "La zona estudiada, sobre la margen izquierda del río Cauca, abarca toda el área que puede recuperarse para la agricultura por medio del drenaje e irrigación... Se trata de una zona adyacente a Cali, con suelos de buena calidad aptos para cultivos diversos, lo que hace que este proyecto revista interés muy especial, tanto desde el punto de vista económico como el sanitario. Los pantanos y ciénagas que cubren actualmente gran parte de la superficie de esta zona, constituyen verdaderos focos de infección que atentan constantemente contra la salud pública de Cali y de los numerosos centros poblados anexos." (OLAP 1950:10).
}

mediante el decreto 3110 de 1954. Su creación se enmarca en los lineamientos seguidos en el modelo precedente del valle del río Tennessee en Estados Unidos (T.V.A.) y en la implementación de politicas nacionales que buscaban dinamizar el sector agrícola del país" (Velásquez \& Jiménez 2004).

El modelo del valle del río Tennessee será central no sólo para la creación de la CVC, sino también para el modelo de desarrollo regional pensado por la élite económica y política que impulsaba este proyecto agroindustrial.

"El surgimiento de la CVC significó darle cabida a un
imaginario de desarrollo de corte moderno puesto que
presupuso definir la región geográfica de cara a la
intensificación de los cultivos y al mejoramiento de las
importaciones; en este contexto la finca tradicional con su
agricultura variada y sus productos de pancoger se ve
arrasada ante la intensificación de los monocultivos y las
relaciones de producción de corte capitalista [...] La
expansión del sistema eléctrico entonces se constituyó como
un instrumento para lograr los objetivos de la política
económica tendiente a dar origen y consolidar la industria
manufacturera y la agroindustria." (Arrechea \& García
2003)

Se evidencia entonces que detrás del surgimiento de la CVC estaba un grupo de políticos locales que movilizaron un plan estratégico de desarrollo regional para recibir el aval y apoyo económico tanto del gobierno Nacional como Departamental, y de inversionistas extranjeros. La puesta en marcha de este plan estratégico de desarrollo regional con el que se pretendía el progreso económico de la región fue impulsado por: José Castro Borrero, Manuel Carvajal, Ciro Molina Garcés, Espíritu Santos Potes, José María Guerrero, Harold Eder, entre otros. El apoyo de la ANDI fue decisivo para la concreción de esta institución. Según la CVC (2004), la realización del Proyecto Aguablanca permitió incorporar tierras para agricultura, dio solución al alcantarillado y habilitó grandes hectáreas de tierras para la solución del problema de vivienda. Además de ello, en el discurso aparece la necesidad de acabar con pantanos y ciénagas que constituyen un problema para la salud pública por los niveles de infección y enfermedades para la población de Cali. Muchas de las microcuencas hidrográficas existentes fueron canalizadas como sucedió con el río Cañaveralejo y luego con el río Meléndez. El crimen ambiental pululó durante la segunda parte del siglo XX puesto que la ciudad creció allí donde no se protegió los diferentes cauces de ríos, zonas de inundación, bosques o áreas pantanosas. Jacques AprileGniset explica que la CVC fue presidida por Harold Éder, uno de los principales terratenientes y dueños de ingenios azucareros, entre ellos el Ingenio Manuelita y del Cauca, luego vendido al empresario Ardilla Lülle en la década de los 
80. Por tanto, realizar estas obras beneficiaría a estas familias que además controlaban espacios de decisión como la alcaldía, las juntas de planificación, el Concejo municipal y la Asamblea departamental. ${ }^{3}$

Además de la CVC, el gremio se vio beneficiado por un conjunto de organizaciones de gran impacto. Una de ellas es la constitución de la Asociación de Cultivadores de Caña de Azúcar de Colombia (ASOCAÑA) en 1959 que tenía por objetivo, representar al sector azucarero colombiano en las negociaciones internacionales. ${ }^{4}$ Luego, aparece la Comercializadora Internacional de Azúcares y Mieles S.A. (CIAMSA) fundada en 1961 y que se encarga de realizar la comercialización y operación logística de la exportación de azúcar y miel. Por iniciativa de Asocaña, hacia 1977 se funda el Centro de Investigación de la Caña de Azúcar de Colombia (CENICAÑA) como una corporación privada sin ánimo de lucro, fundada en 1977. También Asociación Colombiana de Técnicos de la Caña de Azúcar (TECNICAÑA) que es responsable de la permanente capacitación y transferencia de tecnología hacia los técnicos del sector. Se constituye así un clúster agroindustrial que sobre una plataforma territorial dispuesta para el desarrollo gremial.

Desde ese momento se homogeniza el paisaje por la dedicación de importantes áreas al cultivo de la caña, en los departamentos del Cauca, Valle, Risaralda, Caldas y Quindío, Risaralda, abarcando 47 municipios que poseen una condiciones agroclimáticas que fueron favorables para el cultivo de caña de azúcar (Figura 1). La apertura de los mercados y los avances científicos abrió al sector agroindustrial otros mercados como lo es el caso de la producción de agrocombustibles.

\section{Impactos sobre el sistema socioecológico y situación actual}

Tal como quedó evidenciado en el punto anterior, con el aval de la élite política local y regional, así como de los diferentes gobiernos a lo largo del tiempo, se impuso sobre las tierras planas del ecosistema del valle geográfico del río Cauca un modelo de enclave agrícola que consiste en la extracción incesante de caña de azúcar para la producción (Vásquez 1996). Un modelo agroindustrial que en las últimas décadas, mediante la implementación de la apertura de productos en el mercado global y la libre competencia, así como el consumo

\footnotetext{
3 "Diques, canales, obras de drenaje, puentes y alcantarillados se construyen con préstamos monetarios en dólares, desde Juanchito hasta Navarro; van equipando por casualidad las tierras de la antigua hacienda de Meléndez, convertida poco años antes en trapiche panelero y donde se está instalando un moderno ingenio azucarero de exportación. En 1964 se anunciaba que las tierras están recuperadas; según el archivo de Asocaña, fueron "recuperadas" por las familias Garcés Éder y Éder Garcés, principales terratenientes y dueños del ingenio Meléndez." En AprileGniset, Jackques. La ciudad colombiana. Siglo XIX y Siglo XX, 1992 p. 700.

4 Personería jurídica otorgada por el Ministerio de Justicia de Colombia, segúnResolución 0845 del 14 de marzo de 1959.
}

mundial de azúcar, ${ }^{5}$ tiene como objetivo único un intenso acumulativo de excedentes de capital como riqueza a alta velocidad en las redes del mercado global, transformando de modo radical el sistema ecológico de esta zona. La tendencia al incremento del área dedicada a los cultivos cañeros induce efectos de diversa índole:

1. La transformación de un valle rico en tierras con la posibilidad de producción diversa de cultivos que garanticen la seguridad alimentaria, hacia unas tierras dominadas por el monocultivo con excesos en su uso y con la tendencia a ampliar su frontera agrícola. Actualmente existen 13 ingenios azucareros.

2. Una configuración espacial que convierte la región en un panorama ecológico y paisajístico homogenización. Según datos de Asocaña, "actualmente existen 223.905 hectáreas sembradas en caña para azúcar, de las cuales, el $24 \%$ corresponde a tierras propias de los ingenios y el restante $76 \%$ a más de 2.000 cultivadores de caña. Dichos cultivadores abastecen a los 13 ingenios de la región (Cabaña, Carmelita, Manuelita, María Luisa, Mayagüez, Pichichí, Risaralda, Sancarlos, Tumaco, Ríopaila-Castilla, Incauca y Providencia). Desde 2005, cinco de los trece ingenios tienen destilerías anexas para la producción de alcohol carburante (Incauca, Manuelita, Providencia, Mayagüez y Risaralda)" (Asocaña 2013).

3. En la zona plana, existía una variedad de recursos hídricos, en flora y fauna, como parte de un escenario natural valioso que fue removido por la presión de la explotación cañera. El uso desmedido de las fuentes de agua, sobre todo las subterráneas. Una tonelada de azúcar requiere 17 toneladas de agua (Tafur 2008). La actividad de quema de la caña con efectos por contaminación del aire y del sistema de cuencas hidrográficas. Como lo expresa A. Perafán: "Los efectos negativos de esta práctica también se ven reflejados en la fauna y la flora ya que se contaminan los suelos, el aire y las plantas que son posteriormente ingeridas por los animales. Las cenizas que se producen con la quema, debido a la acción de los vientos van a parar a quebradas, ríos, lagos, descargando en ellos sustancias tóxicas que afectan nocivamente los ecosistemas" (Perafán 2013).

4. La sistemática extinción de ecosistemas de humedal existentes por procesos de intensificación de lluvias que producía aumento en los flujos de los ríos y su consecuente desbordamiento sobre las áreas de inundación. Áreas que bajo la lógica de los planificadores y políticos eran lugares

\footnotetext{
5 "El consumo doméstico mundial de azúcar a la misma fecha indicada (Nov2012), alcanzó las 162.80 millones de toneladas métricas, encabezado por la India (15\%), Unión Europea (11\%), China (9\%), Brasil (7\%), Estados Unidos (6\%) y el resto de países 50.66\%.” Blog Económico y Político de Centroamérica.
} 
que merecían ser transformados para su aprovechamiento agrícola o urbano. Para ello se desarrollaron obras, como los jarillones, represas y canales de aguas, que dieron muerte a estos ecosistemas, al cortar el mecanismo natural de inundación. La CVC ha demostrado que entre 1957 y 1986 (es decir, hace ya casi 30 años), periodo del mayor auge cañero en el siglo XX, el Valle del Cauca había perdido el $72 \%$ de sus humedales y el $66 \%$ de sus bosques El hecho ha sido tan grave que en los últimos años, tan solo quedan 8 relictos de bosque y humedal, y todos ellos con tendencia a desaparecer para siempre (Perafán 2013). La misma entidad ambiental $\mathrm{CVC}$, ha reconocido que:

"El alto río Cauca, a su paso por el departamento del Valle del Cauca, conforma lo que se denomina el Complejo Hidrológico del Valle Geográfico. Debido a su formación meándrica y a la dinámica del río, se forman, a lo largo de su recorrido, depósitos en forma de herradura que reciben el nombre de madreviejas. En la década del 50 existían 15286 hectáreas de humedales lénticos en el departamento del Valle del Cauca, a finales de los años sesenta, el 88\% de ellos habia desaparecido, principalmente por la adecuación del espacio para la expansión de los monocultivos de la caña de azúcar, desconociendo los atributos, productos y funciones que cumplen estos ecosistemas. Los principales problemas o amenazas que enfrentan los humedales, son: desecación y drenaje, contaminación, disposición de residuos sólidos y escombros y colmatación, además de otros impactos negativos ocasionados por la construcción de obras civiles. En la actualidad, hay 49 humedales lénticos, remanentes del complejo hidrológico del Alto río Cauca, con aproximadamente 2.500 ha y 2.000 ha de la laguna de Sonso" (CVC 2013).

5. El desplazamiento de comunidades campesinas de la zona plana hacia las zonas de ladera y la configuración de un proletariado agrícola. ${ }^{6}$ La transformación de pequeños agricultores propietarios como obreros de los ingenios azucareros.

6. Obstáculos para el crecimiento de centros urbanos que se encuentran bordeados de plantaciones cañeras como el municipio de Candelaria.

7. Una compleja red vial que conecta las zonas de cultivo con los centros de producción y de transporte hacia la comercialización internacional en puerto y aeropuertos.

\footnotetext{
${ }^{6}$ Proletariado agrícola hace referencia a "trabajadores de los latifundios que venden su fuerza de trabajo por un salario. Entre éstos se encuentran los que se caracterizan por ir de latifundio en latifundio vendiendo su fuerza de trabajo en los períodos de siembra y de cosecha. Son los trabajadores que están en peores condiciones en el campo, debido a que pasan una gran parte del año sin encontrar trabajo y viven en condiciones muy inestables, sin un lugar fijo donde poder establecerse" (Harnecker 1971).
}

8. La construcción de un discurso que argumenta el hecho de que la producción cañera genera desarrollo regional, cuando lo que se evidencia es un desarrollo sectorial.

9. Conflictos por agua para consumo humano. Impacto de la fumigación sobre fincas, cultivos y personas.

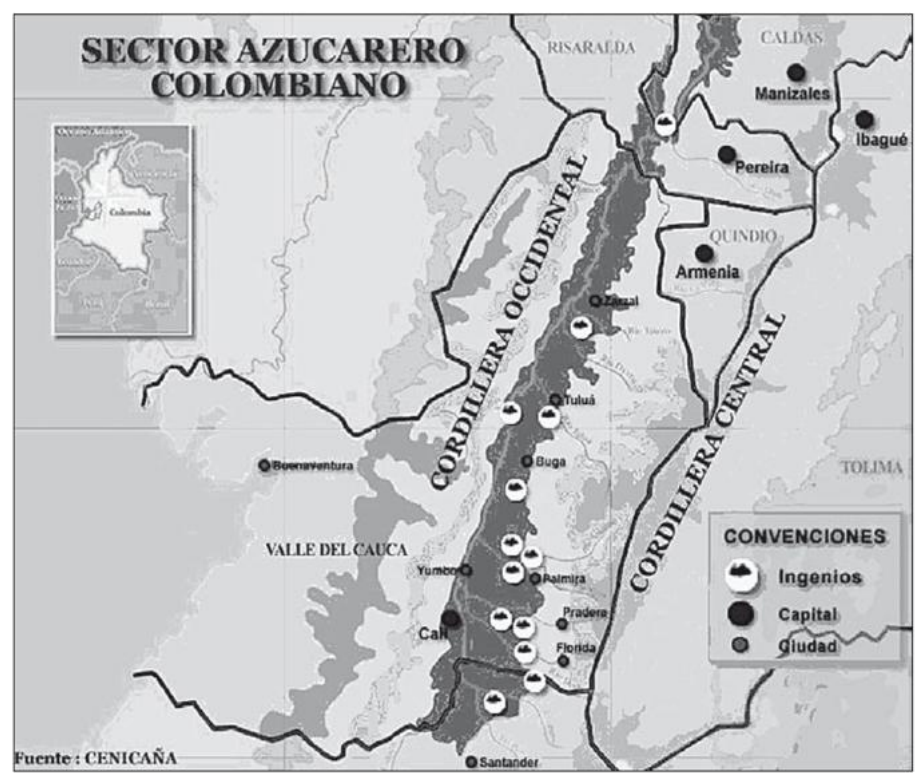

Figura 1. Los ingenios azucareros en el valle biogeográfico del río Cauca. Fuente: Agencia Prensa Rural.

http://prensarural.org/spip/spip.php?article2159

En general, se mantiene la tendencia al incremento del área sembrada de caña de azúcar. Las condiciones de competencia del mercado mundial han conllevado a que el sector de la producción de azúcar sea creativo e innovador. Las políticas del gobierno todavía favorecen este gremio y los proyectos para beneficiar ingenios permanecen. (CVC, 2013).Los pocos ecosistemas que permanecen están amenazados. Otros ya no existen y por tanto se tiene una biodiversidad extinta. Los suelos ya presentan agotamiento y salinidad. Todavía se realizan quemas sobre los cultivos. La evolución natural de los paisajes como imagen de los ecosistemas en cuanto a bosques vírgenes en el valle geográfico fue obstaculizada por las acciones antrópicas.

\section{ACCIONES DE RESISTENCIAS (ENTRE EL AYER Y EL HOY)}

Tal como se ha venido anunciando, el auge y expansión de la caña de azúcar obedeció a la combinación de un conjunto de determinantes políticos y económicos tanto del orden local como global, con repercusiones en el sistema ecológico, en la configuración de poder del territorio a partir de la concentración de la tierra, la dedicación al monocultivo y el modelo rentista y en las condiciones de vida de la sociedad 
asentada en este lugar. Frente a las repercusiones de inequidad y de injusticia social, así como de la falta de distribución del riqueza y del mejoramiento de las condiciones de vida social y ambiental, las comunidades a lo largo del tiempo realizaron acciones colectivas de resistencia de diferentes formas: de defensa, lucha, recuperación o mejoramiento de las condiciones de sus territorios como es el caso de algunas comunidades indígenas y negras; acciones colectivas de tipo laboral como las que se presentaron a lo largo del todo el siglo XX y que aun en épocas más recientes todavía se presentan.

\section{Lucha, recuperación y mejoramiento del territorio}

En este lugar, entre 1851 y 1920, se fue consolidando económica y demográficamente un campesinado negro de pequeños y medianos propietarios de fincas generalmente superiores a las tres hectáreas dedicados a los cultivos del cacao y de productos agrícolas comercializados en las plazas de mercado de Cali (Hurtado 2000). Al presentarse la capitalización de la tierra rural, según Renata Moreno, esto:

\begin{abstract}
"desfavorecerá los poblados prósperos de los campesinos negros y generará muy fuertes tensiones sobre la tierra. Estas circunstancias serán asumidas muy desigualmente por indigenas y negros, los primeros responderán mediante la revitalización de una organización autónoma y la lucha colectiva no sólo por resistir sino por recuperar ahora sí territorios, mientras los segundos, avocados a una más fuerte presión por estar asentados en las tierras planas que son las de mayor interés económico para la agroindustria azucarera, verán descomponer y reducirse su economía campesina a la vez que se transforman en el proletariado vinculado a los nuevos empresarios capitalistas agrícolas. Suelos que antes pertenecían a fincas de campesinos negros pasan ahora a ser parte de empresas capitalistas, quedando así desvinculados en su mayoría de la tierra (Moreno 2004).
\end{abstract}

La presencia agroindustrial desplazó la diversidad de productos y transformó gran parte de la población como proletarios agrícola, mientras que otros se dieron en la tarea de la lucha por la apropiación de tierras a través de asociaciones que utilizarán el repertorio y/o modalidad del bandalismo para defender sus parcelas. Las comunidades negras y las comunidades indígenas participaron, por ejemplo, de la recuperación de algunas haciendas como López Adentro y El Pílamo 13, la cual fue adjudicada a los ocupantes en la modalidad de propiedad mixta gracias a la fuerte presión de la alianza indígena-negra (Hurtado 2004). Frente a esto, autoras como Moreno (2004), consideran que:

"En este contexto el fuerte movimiento indigena que lideraba las recuperaciones incentivó y contribuyó a la acción de algunos de estos pobladores rurales y urbanos negros. Así, a mediados de los ochentas algunos negros participan con indígenas en la recuperación de la hacienda López Adentro en la zona norte que es cuando se produce el primer enfrentamiento con los empresarios del Valle del Cauca trayendo como consecuencia el aumento de la militarización, igualmente se realiza la invasión de la hacienda El Pílamo13 en esta misma zona por parte de pobladores negros en alianza con campesinos indígenas Paéz con el objetivo de recuperar tierras agrícolas para la producción campesina. En 1981 además, cerca de unas 1.500 familias de Puerto Tejada invaden un lote de propiedad del Ingenio La Cabaña y resisten los intentos de desalojo de la fuerza pública" (Moreno 2004).

No obstante, la fuerza del capital transformó con el paso de los años el paisaje de este sector y conllevó a que las luchas ahora fueran más urbanas por reivindicación relacionadas con servicios públicos domésticos y condiciones laborales desde el movimiento sindical (DeRoux 1991). La participación política en el Congreso a partir de representantes fue parte de las acciones estratégicas pero que no lograron tener fuerte impacto cuando las reivindicaciones se hacían frente a los ingenios azucareros. ${ }^{7}$ Para autores como Teodora Hurtado, los líderes políticos representantes de las comunidades negras no lograron sostener las reivindicaciones de la comunidad así como tampoco el apoyo suficiente de los gamonales tradicionales. El resultado es el desencanto, la incredulidad y el desvanecimiento de las organizaciones campesinas que desaparecen (Hurtado 2000).

\section{"Los líderes cívicos y comunitarios formados en el anterior proceso van a conformar nuevas organizaciones. En 1981 aparece el Movimiento Cívico Popular Nortecaucano (MCPN) como resultado de la articulación de un conjunto de organizaciones que habian participado en los procesos de lucha anteriores movilizando importantes sectores de la población. Este movimiento pretendia ser amplio, independiente de los partidos tradicionales; sin tener una plataforma política definida, su discurso se centraba en el rechazo al clientelismo y la discriminación, en la reivindicación de intereses populares y la solidaridad (De Roux, 1991). Pese a su capacidad para dinamizar procesos y luchas sociales, cuando se lanzan al terreno electoral,}

\footnotetext{
7 "Las luchas más importantes llevadas a cabo por estos pobladores son las protestas cívicas realizadas en los años $70 \mathrm{~s}$ y $80 \mathrm{~s}$ alrededor del problema habitacional y de servicios públicos que afectan la calidad de vida de los campesinos, asalariados rurales y residentes urbanos. Estos, con el apoyo de sectores de la Iglesia Católica, simpatizantes de la izquierda y organizaciones universitarias, le demandan soluciones al Estado por medio de acciones llevadas a cabo por distintas organizaciones cívicas populares dentro de un contexto nacional de protestas sociales. También se presentaron por primera vez demandas en contra de los impactos negativos ambientales causados por la caña de azúcar en áreas campesinas como en barrios populares cercados por este cultivo." (Moreno, 2004).
} 
aprovechando la apertura democrática con la reforma que permitía la elección popular de alcaldes, las bases populares no les otorgan el respaldo correspondiente" (Moreno 2004).

En el 2005, se presentaron protestas en el municipio de Caloto, cuando el 8 de mayo, cerca de 1.500 indígenas provenientes de los resguardos Huellas, López Adentro y Toez, en alianza con afrodescendientes expresaron su inconformidad por el proyecto de privatización del agua municipal. Según las autoridades indígenas:

\begin{abstract}
"Se pretende aislar los nacederos de agua, comprando tierras y prometiendo trabajo a los habitantes cercanos, para después entregar los nacederos a la CRC. Una vez los reciba ésta les pondrá un medidor para vender el agua a los campesinos e indígenas. Luego vendrá una empresa internacional que asumirá todo el proyecto ya instalado. Ellos pretenden que las grandes empresas aquí instaladas (ingenios) continúen sin pagar el agua con que riegan sus campos de caña de azúcar, pero que la población sí pague, que los financiemos. Nosotros tenemos la plena certeza de que el agua es un bien común y no puede ser privatizada"(Reyes, 2005).
\end{abstract}

Las protestas por el agua todavía se presentan. Por ejemplo, el caso de los habitantes del Tiple en Candelaria cuando protestaron por el pésimo servicio de agua potable y las repercusiones que ésta tenía sobre la salud de los pobladores, pues el agua subterránea presentaba turbiedad y contenido de metales. ${ }^{8}$ Las protestas que 2008 hasta el presente expresan las inconformidades con el servicio básico de agua en la que interviene problemas de decisión política local, negociación de terrenos que se requiere para colocar las redes de acueducto pero que por estar cultivados con caña no ha sido posible concretarse como acontece con los pobladores y comunidades rurales, como las del corregimiento de Villagorgona en Candelaria. ${ }^{9}$

\section{Resistencias mediante huelgas laborales, sindicales y comunitarias}

Las protestas y acciones colectivas contenciosas también han estado a cargo del proletariado agrícola cañero y sus familias. Ricardo Sánchez Ángel (2008), señala que en el transcurso de la historia se han presentado varias huelgas con repercusiones negativas como despidos y muerte de los trabajadores, intervención de autoridades locales y nacionales, así como el uso desmedido de la fuerza pública.

\footnotetext{
8 "El agua de candelaria no es apta para el consumo humano". EL PAIS, agosto 5 de 2008.

9 "Decretan emergencia sanitaria en Villagorgona por falta de agua potable", EL PAIS, noviembre 18 de 2013.
}

Algunas de ellas de especial importancia acontecieron desde los años treinta cuando en 1936 con la primera huelga y un año después de surgido el primer sindicato en 1935; la huelga de 1944 que se da con la creación de más sindicatos; las huelgas del Papayal en 1960 y la huelga de la Hacienda San José en 1964; luego en 1973 cuando el 27 de diciembre se dio el paro de corteros y alzadores de caña de Tesorito. Paro que fue reanudado en enero de 1974 que logró la reincorporación de los trabajadores despedidos meses atrás y la intervención del Ministerio de Trabajo. También el paro de 1975 y luego en 1976 con la huelga en el ingenio Rio Paila en la que asesinaron dos trabajadores, que implicó la intervención del Presidente de turno y que conllevó a la conformación de formas organizativas más allá del sindicato y donde el papel de la mujer fue central.
"En verdad, se trata no de una huelga en Riopaila, sino de varias con epicentro en distintos ingenios y trapiches, en que el Ingenio Manuelita fue la matriz inicial de la industria y de las huelgas. Las dos grandes movilizaciones aqui estudiadas tuvieron como motor a Riopaila $y$ sacudieron la sociedad señorial-burguesa del Valle del Cauca, con repercusiones en la política nacional y en la conciencia de los trabajadores en el país" (Reyes 2008).

También se presentaron algunas huelgas como las ocurridas en 2008 entre el empresariado cañero y los corteros y que fueron estudiadas por Pérez y Álvarez (2009), Jaramillo Ferro (2011) y luego por Uribe \& Montoya (2012).

\section{Resistencias defendiendo la naturaleza}

Ahora bien, con respecto a las luchas por la naturaleza, se tiene el artículo publicado por el CIDSE titulado Destrucción ambiental y resistencia de Klauss Meschkat (1983). En la obra en mención, el propósito es presentar casos ejemplares que muestran la relación entre la destrucción ambiental y las formas de resistencia social. La tesis del profesor es que la destrucción del ambiente natural se incrementa a gran velocidad en aquellos países considerados como de capitalismo dependiente, siendo Colombia un claro ejemplo del ritmo catastrófico del deterioro ecológico. Fenómeno producido por la depredación de selvas tropicales, zonas dedicadas al monocultivo, empleo irrestricto de herbicidas y pesticidas, polución del agua, desechos industriales, vertimientos sobre los ríos y contaminación atmosférica.

Además del conjunto de preocupaciones mencionadas, el autor hace un abordaje a tres casos específicos de pueblos resistiendo los impactos de actividades económicas como la extracción de azufre en el volcán Puracé sobre territorio indígena, la fábrica de ácido Sulfúrico de Caloto, el conflicto ambiental en la laguna de sonso en Buga y los efectos de la caña de azúcar en distintos lugares del Valle del Cauca. 
En el primer caso, el Meschkat (1983) muestra como las comunidades indígenas inician una lucha frontal contra la empresa Puracé, accionista de la empresa extractiva de azufre, por los efectos que las nubes de gases sulfurosos tenían sobre la tierra, el agua, los animales, las plantas y la comunidad. Las denuncias realizadas por los indígenas fueron confirmadas por intelectuales y científicos de las universidades del Valle y la del Cauca. Las protestas tanto de los mineros del azufre como de las comunidades indígenas terminaron en bloqueos de vías departamentales, parálisis de la producción. El resultado es la firma de un acuerdo de indemnización del resguardo por perjuicios. La empresa logró dividir el movimiento y forjó la división entre mineros e indígenas. Finalmente la empresa, mediante hábiles maniobras eludió sus obligaciones y el cierre de la mina. Los indígenas, a pesar de no haber recibido la indemnización prometida, si lograron con este movimiento una mejor organización, que incluso hoy existe, como lo es el Consejo Regional Indígena del Cauca (CRIC).

El segundo caso es el de la fábrica de ácido sulfúrico de Caloto. Esta fábrica tiene sus orígenes en otra fábrica urbana, "Industrias Quin S.A.", localizada en Cali cuyo funcionamiento generaba polución ambiental. La comunidad logró que el Ministerio de Salud paralizara la fábrica. Los accionistas cambiaron la razón social de la empresa y ubicaron su nueva sede en el Municipio de Caloto en el Cauca, en 1981. La instalación de la empresa llevó a que las comunidades se organizaran y mediante movimientos locales como el "Movimiento Cívico "Popular Norte Caucano", llevaran a cabo estrategias para enfrentar estos problemas.

Finalmente el tercer caso presentado hace referencia a la Laguna de Sonso, que enfrenta la devastación ecológica en nombre del desarrollo urbano así como por el desarrollo del sector agroindustrial. Esta era un espacio con importante biodiversidad, actividades campesinas tradicionales de pesca y proveedora de alimento para las comunidades cercanas. Algunos terratenientes con capacidad de incidir en las decisiones institucionales han pretendido exterminar la laguna para sus intereses personales. Frente a esto, grupos el de Activistas Ecológicos, organizaciones ambientales e intelectuales de las Universidades de la región se han dado en la tarea de la defensa de la laguna. Incluso, entes como Fundavalle, surgieron en el marco de estas luchas, y desde las cuales se promovieron importantes marchas como la del 15 de agosto de 1981. Finalmente, las conclusiones recogen y sintetizan el desarrollo de la tesis, indicando

"Es cierto que las consecuencias existenciales de tal deterioro son muchos más grandes en las naciones industrializadas, precisamente para las capas inferiores de la sociedad, porque una tierra que ya no se puede cultivar significa hambre para el labriego pobre, porque la mortalidad del pescado en los ríos contaminados amenazan una parte importante del abastecimiento de proteínas animales para la población, porque el consumo de agua contaminada producen enfermedades y epidemias en forma inmediata (y no sólo a largo plazo). Pero el deterioro ambiental es solamente una de las amenazas existenciales que provoca el capitalismo dependiente" (Meschkat 1983).

El otro artículo en esta misma perspectiva es el de Isaías Tobasura (2006) sobre el caso específico de la laguna de Sonso, que ya había sido abordada por Aníbal Patiño en la ponencia titulada Reserva Natural Laguna de Sonso (Buga) (1978-1988). De laguna a pantano en diez años. Balance crítico y juicio de responsabilidades, y que fue presentada en el $5^{\circ}$. Congreso de la Sociedad Colombiana de Ecología en la ciudad Bogotá en 1998.

El artículo de Tobasura (2006) se titula La Laguna de Sonso Valle del Cauca, Colombia: Más de tres décadas de lucha ambiental. Un caso de historia ambiental. En este texto se parte con la idea de que pocos esfuerzos han existido con respecto a tratar los procesos físico-biológicos como hechos históricos. El autor se propone entonces analizar uno de los casos más emblemáticos del ambientalismo desde la perspectiva de la historia ambiental como lo es el caso de la lucha por la defensa de la laguna de Sonso llevada a cabo por la comunidad local, pescadores, movimiento estudiante e intelectuales.

El autor inicia su estudio haciendo referencias a las características de la laguna de Sonso, su historia, su configuración espacial e importancia. Luego identifica el momento de quiebre que conllevó a que la laguna iniciara a afectarse por la construcción de un jarillón que impidió el ingreso del agua del río hacia la laguna y que posibilitó el surgimiento de vegetación acuática que se amplió en gran parte de ella. Del mismo modo, la laguna se ha visto amenazada por el desarrollo capitalista, y particularmente, por la agricultura de la caña de azúcar, "al punto que es el único cuerpo de agua que sobrevive al desecamiento de pantanos y madres viejas en el Valle del Cauca." (Tobasura 2006). No obstante, frente a esos riesgos, las autoridades competentes, tanto el Ministerio como la CVC, nada hicieron para mejorar estas condiciones. Desde ese entonces, se han evidenciado grupos interesados en hacer la defensa del humedal. Para el profesor Tobasura,

"La defensa de la Laguna de Sonso se ha caracterizado por
utilizar como "repertorio de acción" la denuncia respetuosa
y científicamente argumentada ante las autoridades y las
instituciones, a través de los medios de comunicación, las 
declaraciones escritas, las marchas, las jornadas ecológicas y la sensibilización de la comunidad. Los ecologistas han actuado como grupo de presión ante las instituciones para favorecer la promulgación de ciertos tipos de leyes, o forzar la aplicación de otras; han acudido a la acción directa o a los tribunales para frenar proyectos que sean perjudiciales para el medio ambiente. La defensa de Sonso sintetiza estas formas clásicas de la acción colectiva" (Tobasura 2006).

El horizonte teórico del autor, aunque no se citan de modo directo en el texto, está enmarcado en la perspectiva de la movilización de recursos y de las oportunidades políticas de Charles Tilly y Sidney Tarrow, donde éste último propone la perspectiva tanto de los marcos de la acción colectiva como el ciclo de las protestas. El profesor Tobasura identifica tres ciclos de análisis en la lucha por la laguna de Sonso: Un primero ciclo, de los años setenta, liderada por académicos que desde sus argumentos científicos dan la batalla con argumentos ecológicos para la defensa de este espacio. En esta parte es central el papel de la investigación y los estudios académicos, así, como las jornadas, foros y eventos como estrategias para visibilizar el conflicto y esclarecer los responsables directos y del Estado. Un segundo ciclo, donde las bases académicas se mantienen y se convierten en soportes para la movilización social. En esta parte la estrategia es la creación de Fundaciones como medios para la facilitar y motivar la organización social cuyo efecto fue atraer la atención de los diferentes medios de comunicación y de la sociedad en general. Un tercer ciclo, donde las bases de la movilización social dan un paso hacia la denuncia legal.

"El 18 de agosto de 1987, Patiño envió una carta al Director Regional del Incora, para expresarle la preocupación que existe con relación a la falta de claridad que tiene la CVC "[...] en relación con lo que debe ser considerado como propiedad pública dentro del área de reserva, de acuerdo con las leyes [...]" desconociendo la propiedad pública de la faja hasta de treinta metros en contorno, de acuerdo con lo establecido en el artículo 83 del Decreto 2811 de 1974. La falta de claridad de la CVC o su complacencia ha estimulado a algunos propietarios contiguos para correr sus cercos a medida que se retira el nivel de las aguas, afectando el área lagunar. En consecuencia, le solicita al Incora que clarifique los linderos de la reserva natural, delimitando la propiedad social de la propiedad privada, para impedir que los vecinos se sigan apoderando de los bienes públicos" (Tobasura 2006).

Finalmente las conclusiones del autor recogen y sintetizan el desarrollo de su trabajo al considerar que después de tres décadas, las condiciones ecológicas de la laguna de Sonso como de los restantes humedales de la región siguen en deterioro. A pesar de todo ello, la lucha por la laguna ha permitido que aún exista y esté viva. El hecho de que existan otras organizaciones que la protejan así como el ojo vigilante de sus comunidades vecinas, permiten pensar que la movilización social de una generación anterior fue efectiva. Todavía se realizan eventos, foros y congresos donde se pone el caso de la laguna de sonso como un ejemplo emblemático de resistencia socioambiental. Todavía existen grupos de interés, elites políticas y económicas que consideran los ecosistemas de humedal como espacios que deben eliminarse para aprovechar esas tierras productivas. Así, el autor define que este es un buen ejemplo de ambientalismo popular, que combina la lucha popular con las acciones de los nuevos movimientos sociales en términos de los actores participantes, estrategias repertorios y ciclos de protesta, que ayudan a construir la identidad colectiva ambiental.

\section{UNA ÚLTIMA REFLEXIÓN}

El auge de la caña de azúcar sobre el valle geográfico del río Cauca ha presentado importante incidencia sobre el sistema socioecológico que integra los elementos sociales con las condiciones naturales del lugar. Desde una perspectiva sistemática, la relación entre los factores estructurales del sistema de la política económica mundial y su incidencia en Colombia y la región, fueron elementos determinantes e incidieron en el conjunto de condiciones favorables para el mercado de azúcar y el incremento de su producción en Colombia. Estas condiciones favorables de la política económica van a contribuir a que las empresas agroindustriales incrementen las áreas sembradas y la producción de azúcar con efectos claros en el uso del suelo del valle geográfico del río Cauca y ecosistemas de humedal (en el agua, el aire, el suelo y el subsuelo), así como en los grupos humanos que se vieron obligados a migrar a la ciudad, o se convirtieron en mano de obra asalariada de los ingenios como corteros de caña (proletarios agrícolas), o todavía son comunidades que resisten los embates de las nocivas consecuencias del cultivo y producción de la caña de azúcar. Estos elementos se tratan de mostrar en el gráfico que se encuentra anexo (Anexo 1).

Se está, entonces, ante un hecho concreto y empírico que evidencia un incremento sustancial de la ampliación de la frontera cañera sobre el territorio en el largo plazo y la transformación radical del paisaje y sus ecosistemas (bosques secos y húmedos) que desaparecieron para dar paso a la homogenización paisajística. Como lo expresa Aceneth Perafán "Todo ello ha ocurrido en el contexto de un proceso de explotación que se tornó más agudo en la pasada centuria, período en el cual la pérdida de muchos hábitats se aceleró de manera alarmante." (Perafán 2013). Las comunidades han presentado a lo largo de los años diversas formas de resistencia que reivindican el derecho al territorio, la defensa frente a las afectaciones ambientales y el reclamo por la pauperización de la propia vida de los trabajadores que laboran en los ingenios. La victoria la poseen los ingenios que 
se mantienen en el lugar, que continúan con su modelo productivo de clúster y enclave agrícola, y que han fortalecido su producción con grandes repercusiones en el uso, acceso y empobrecimiento de la calidad del agua, la contaminación del aire y de los suelos, así como la pérdida de la biodiversidad regional.

De parte del Estado, se carece de controles eficientes y directos sobre este proceso de ampliación. Contrariamente, se evidencia un apoyo e incentivos al sector agroindustrial. Como lo exponen Navarro (2009), “el Estado surge como principal impulsor de los proyectos de desarrollo y explotación de la mano de la empresa e inversores que son menos visibles, aunque en varias fases del conflicto, puede apreciarse su influencia y poder sobre el procedimiento de aprobación y decisión". Las comunidades continúan enfrentado los embates. Interesa preguntarse por qué existiendo una Corporación Autónoma Regional del Valle del Cauca encargada del bienestar socioambiental de toda la región desde mediados del siglo $\mathrm{XX}$, exista en este territorio el uso exagerado de la tierra al monocultivo cañero. Pareciera que contrariamente, entidades del Estado como la CVC lograron incidir en este repunte del desarrollo sectorial cañero que se pretende mostrar como desarrollo regional, con todos los efectos sociales, ambientales y de inequidad que tuvo la ampliación de la frontera de la caña de azúcar en la región.

\section{REFERENCIAS}

APRILE-GNISET, J. 1992. La ciudad colombiana. Siglo XIX y Siglo XX. Fondo de Promoción de la Cultura del Banco Popular, Bogotá. p. 798.

ARRECHEA, M. GARCIA, G. 2003. Tradición y modernidad: una relación dialéctica en la conservación de las madreviejas la guinea y guarino, municipio de Jamundí., Facultad de Humanidades. Departamento de Trabajo Social, Universidad del Valle, Colombia.

CORPORACIÓN AUTONOMA REGIONAL DEL VALLE DEL CAUCA. 2004. Génesis y desarrollo de una visión de progreso. Cali: CVC. 303pp.

DE-ROUX. G. 1991. Orígenes y expresiones de una ideología liberal. Boletín Socioeconómico (Cali), No. 22. 1-26p

ESCOBAR, A. 1999. El final del salvaje. Naturaleza, cultura y política en la antropología contemporanea. CEREC, Santafe de Bogotá. 418pp.

FOEI. 2008. Fomentando la destrucción en América Latina. El costo real de la ofensiva de los agrocombustibles. Amigos de la Tierra, FOEI, Holanda, (113): 48p.

GARCÍA, C. I. 2004. Resistencias. Análisis comparado de la acción colectiva frente a la guerra en Urabá y oriente antioqueño. Nómadas, Colombia, 20: 102-110.

HARNECKER, M. 1979. Clases sociales y luchas de clase. Cuadernos de la memoria. Akal. 35p.

Hurtado T. 2001. La protesta social en el Norte del Cauca y el surgimiento de la movilización étnica afrocolombiana. Pardo Mauricio (edit.), Acción colectiva, Estado y etnicidad en el Pacifico colombiano, Colciencias, Instituto Colombiano de Antropología e Historia. Bogotá,

HOLLING, C.S. 2001. Understanding the complexity of Economic, Ecological and social systems.In: Ecosystem. (4): 390-405.

JARAMILLO, J. E. 2011. El paro de los corteros de la caña de azúcar 2008: un análisis desde la perspectiva de la acción colectiva. Instituto de Educación y Pedagogía, Estudios políticos y Resolución de Conflictos. Universidad del Valle. CD-ROM archivo PDF.

LEFF, E. 2001. Saber ambiental: sustentabilidad, racionalidad, complejidad, poder. Siglo XXI. México DF, México. 414p.

LEFF, E. 2003. La ecología política en América Latina. Sociedade e Estado, Brasilia, 18(1/2): 17-40.

MESCHKAT. K. 1983. Destrucción ambiental y resistencia. Boletín socioeconómico No. 10. Universidad del Valle, Facultad de Ciencias Sociales y Económicas. Cali. 47-84pp.

MORENO, R. 2004. Los movimientos étnicos en el norte del Cauca, una aproximación a sus diferencias y relaciones. Colombia, artículo de investigación dentro de las becas de Clacso.

NAVARRO, M. L., \& PINEDA, C. 2009. Luchas socioambientales en América Latina y México. Nuevas subjetividades y radicalidades en Movimiento. Bajo el Volcán, 8(14): 81-104.

OSPINA, OLARTE, ARIAS \& PAYÁN, LTDA. 1951. Proyecto de Aguablanca. Control de inundaciones, drenaje y riego. Valle del Cauca, Planeamiento de recursos naturales. Ospina, Olarte, Arias \& Payán, Ltda. OLAP. 90pp

PALACIO, G. \& ULLOA, A. (Editores). 2002. Repensando la Naturaleza. Universidad Nacional - Imani - ICANH Colciencias, Bogotá. 246pp 
PERAFÁN, A. 2013. Valle del Cauca: un estudio en torno a su sociedad y medio ambiente. Colombia: Centro Editorial de la Universidad de Valle. Cali. 450 pp

PÉREZ, M. A. \& ÁlVAREZ R, P. 2009. Deuda social y ambiental del negocio de la caña de azúcar en Colombia: responsabilidad social empresarial y subsidios implícitos en la industria cañera. Análisis en el contexto del conflicto corteros-empresarios. Campo Semillas y Swizar, Bogotá. 70 pp.

ROJAS, J. M. 1983. Sociedad y economía en el Valle del Cauca. Empresarios y tecnología en la formación del sector azucarero en Colombia, 1860-1980, Tomo V. Biblioteca Banco Popular, Bogotá. 115-162pp.

SALAS Z, W. RÍOS O, L. \& ÁlVAREZ, J. 2012. Bases conceptuales para una clasificación de los sistemas socioecológicos de la investigación en sostenibilidad. Revista Lasallista de Investigación, 8(2): 136-142 pp.

SANCHEZ, R. 2008. Las iras del azúcar: la huelga de 1976 en el Ingenio Riopaila. Historia Crítica, 35: 34-57

SANTOS, A. \& SÁNCHEZ, H. 2010. La irrupción del capitalismo agrario en el Valle del Cauca, 1900-1950. Programa Editorial de la Universidad del Valle, Colombia. 125pp.

SÁENZ, O. (Compilador) 2007. Las ciencias ambientales: una nueva área del conocimiento. Tesis y propuestas. Red Colombiana de Formación Ambiental. Bogotá, Colombia. 182 pp.

TILLY, C. 1974. An Urban World. Boston: Little, Brown and Co. 487pp.

TILLY, C. 1978. From mobilization to revolution. Addison Wesley, Cambridge, Harvard University Press. 349 pp.

TISCHLER, S. \& NAVARRO, M. 2011. Tiempo y memoria en las luchas socioambientales en México. Desacatos, 37: 67-80.

TOLEDO, V. 1990 Modernidad y Ecología. Revista Ecológica, Icaria, 3: 9-22.

TOBASURA A., I. 2006. La Laguna de Sonso - Valle del Cauca, Colombia: Más de tres décadas de lucha ambiental. Un caso de historia ambiental. Gestión y Ambiente, 9(2): 1326.

URIBE C., H. \& MONTOYA, G. 2011. El espacio como lugar en la acción colectiva. Universidad Autónoma de Occidente,
Cali.112 pp

VÁSQUEZ S., J. 2000. Geografía rural y de la agricultura. Universidad del Valle, Cali. 274 pp.

VÁSQUEZ, E. 1996. Panorama histórico de la economía vallecaucana en el siglo XX. Alonso Valencia Llano, Ed.: Historia del Gran Cauca. Historia regional del suroccidente colombiano. Universidad del Valle. Cali.

VELÁSQUEZ, A. \& JIMÉNEZ, N. 2004. La gestión del riesgo en el ordenamiento territorial: las inundaciones en Cali, la CVC. y el fenómeno ENSO. Seminario Internacional Ambiental, CVC 50 años. Cali. 18 pp.

WOLF, E. 1972. Ownership and Political Ecology. Antropolgical Quarterly, 45(3): 201-205.

WEBGRAFÍA

ASOCAÑA. Sector Azucarero en Colombia. (Fecha de acceso 20 de mayo de 2014) URL disponible en:

http://www.asocana.org/publico/info.aspx

BERMÚDEZ, I. C. 1997. La caña de azúcar en el Valle del Cauca. En: Orígenes de la industria en Colombia 1850-1950. Credencial Historia. (Fecha de acceso 16 de junio de 2014); (92). URL disponible en:

http://www.banrepcultural.org/node/73662

CORPORACIÓN AUTONOMA REGIONAL DEL VALLE DEL CAUCA. 2013. ¿Qué son los humedales?, Cali: Corporación Autónoma Regional del Valle del Cauca. (Fecha de acceso el 25 de noviembre de 2013) URL disponible en: http://www.cvc.gov.co/portal/index.php/es/tematicas/bio diversidad/humedales

REYES, RUBEN D. El pueblo elige, el pueblo exige. (Fecha de acceso el 12 diciembre de 2013), URL disponible, http://www.voltairenet.org/article126013.html. 
Ambiente y Sostenibilidad 2014 (4): 16-30

Revista del Doctorado Interinstitucional en Ciencias Ambientales

ISSN: 2339-3122

Anexo 1. Sistema socioecológico e implicaciones de la expansión cañera en el valle geográfico del río Cauca (Fuente Propia).

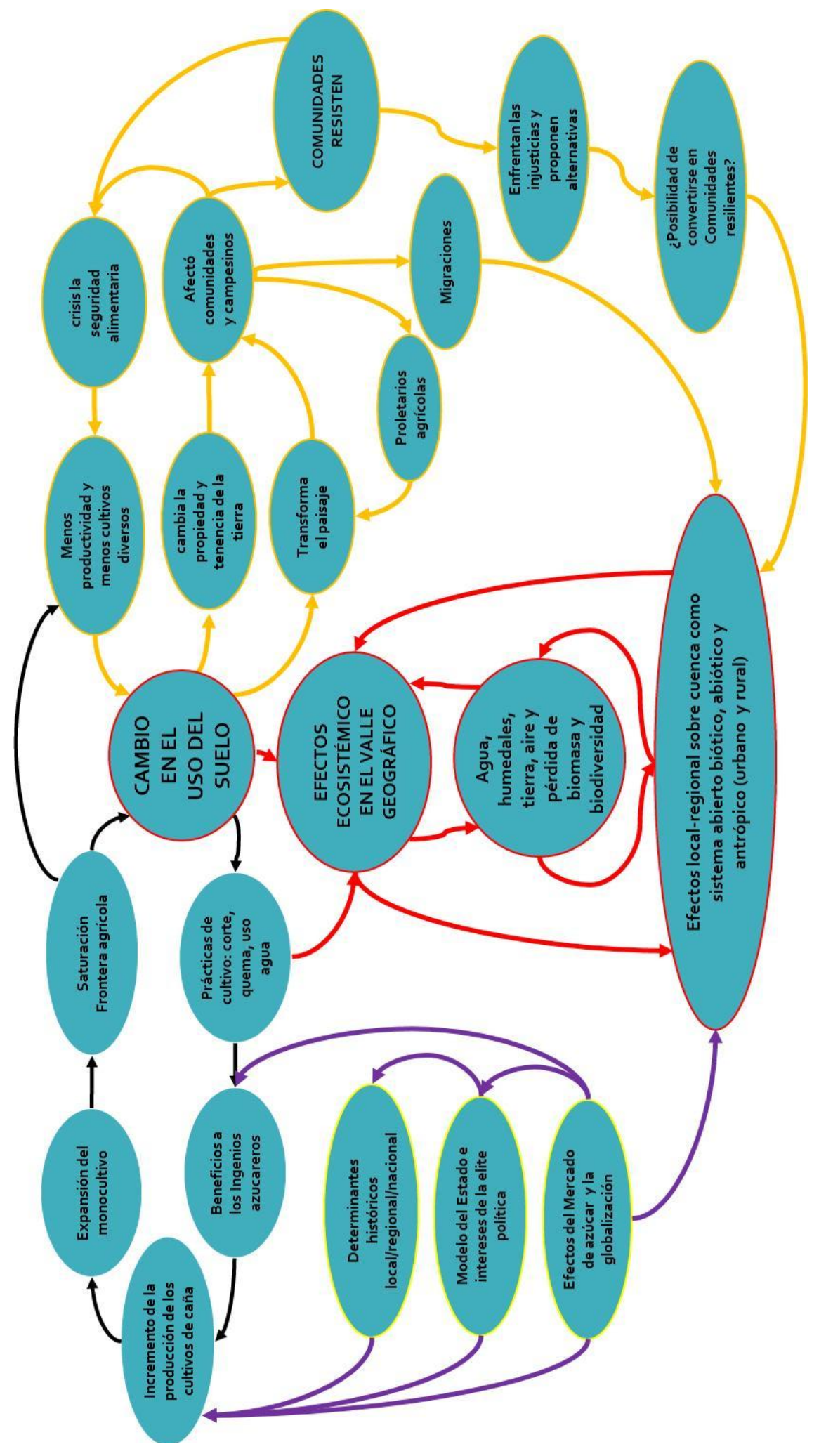

